\title{
Mapping quantitative trait loci affecting fatness and breast muscle weight in meat-type chicken lines divergently selected on abdominal fatness
}

\author{
Sandrine LAGARRIGUE ${ }^{\mathrm{a}}$, Frédérique PITEL ${ }^{\mathrm{b}}$, Wilfrid CARRÉc ${ }^{\mathrm{c}}$, \\ Behnam ABASHT ${ }^{\mathrm{a}}$, Pascale Le RoY ${ }^{\text {ad }}$, André NEAU ${ }^{\mathrm{e}}$, \\ Yves AMIGUES $^{\mathrm{f}}$, Michel Sourdioux ${ }^{\mathrm{a} *}$, Jean SIMON ${ }^{\mathrm{g}}$, \\ Larry COGBURN ${ }^{\mathrm{c}}$, Sammy AGGREY ${ }^{\mathrm{h}}$, Bernard LECLERCQ ${ }^{\mathrm{g}}$, \\ Alain VIGNAL ${ }^{\mathrm{b}}$, Madeleine DOUAIRE ${ }^{\mathrm{a} * *}$ \\ ${ }^{a}$ UMR Inra-Agrocampus génétique animale, 35042 Rennes, France \\ ${ }^{\mathrm{b}}$ Laboratoire de génétique cellulaire, Inra, 31326 Auzeville, France \\ ${ }^{\mathrm{c}}$ Department of Animal and Food Sciences, University of Delaware, Newark, DE 19717, USA \\ d SGQA, Inra, 78352 Jouy-en-Josas, France \\ ${ }^{\mathrm{e}}$ Department of Animal Genetics, Inra, 78352 Jouy-en-Josas, France \\ ${ }^{\mathrm{f}}$ Labogena, 78352 Jouy-en-Josas, France \\ ${ }^{g}$ Station de recherches avicoles, Inra, 37380 Nouzilly, France \\ ${ }^{\text {h }}$ University of Georgia, Athens, GA 30602, USA
}

(Received 28 February 2005; accepted 18 August 2005)

\begin{abstract}
Quantitative trait loci (QTL) for abdominal fatness and breast muscle weight were investigated in a three-generation design performed by inter-crossing two experimental meattype chicken lines that were divergently selected on abdominal fatness. A total of $585 \mathrm{~F}_{2}$ male offspring from $5 \mathrm{~F}_{1}$ sires and $38 \mathrm{~F}_{1}$ dams were recorded at 8 weeks of age for live body, abdominal fat and breast muscle weights. One hundred-twenty nine microsatellite markers, evenly located throughout the genome and heterozygous for most of the $F_{1}$ sires, were used for genotyping the $\mathrm{F}_{2}$ birds. In each sire family, those offspring exhibiting the most extreme values for each trait were genotyped. Multipoint QTL analyses using maximum likelihood methods were performed for abdominal fat and breast muscle weights, which were corrected for the effects of 8-week body weight, dam and hatching group. Isolated markers were assessed by analyses of variance. Two significant QTL were identified on chromosomes 1 and 5 with effects of about one within-family residual standard deviation. One breast muscle QTL was identified on GGA1 with an effect of 2.0 within-family residual standard deviation.
\end{abstract}

quantitative trait locus / abdominal fat / breast muscle /chicken

${ }^{*}$ New address: Gene+, 62134 Erin, France

** Corresponding author: Madeleine.Douaire@ rennes.inra.fr 


\section{INTRODUCTION}

Fat deposition has been investigated for many years in the chicken for its negative impact on feed efficiency, nitrogen retention and lean meat yield [16]. Lean chickens have better protein efficiency than fat ones [15] which also excrete more nitrogen [5]. More recently, there has been an increased interest in fatness of farm animals in developed countries because of a higher demand for reducing fat intake in the human diet.

Fatness is a highly heritable trait with heritability ranging between $0.5-0.8$ and genetic selection has given rise to highly divergent lean (LL) and fat (FL) chicken lines [16]. However, commercial selection against this trait has not been widely used due to the difficulty and cost of slaughtering and dissection in sib-test assays. Alternatively, the use of molecular genetic information could facilitate selection against fatness after quantitative trait loci (QTL) or, even better, the genes responsible for variability in the trait have been identified. The development of molecular markers and genetic maps for the chicken $[7,26]$ has allowed initial identification of chicken QTL for carcass traits [30-32]. QTL for fatness have been found in various crosses between different breeds of chickens. Tatsuda and Fujinaka [27] have used crosses between slow-growing (meat-type) native Japanese breeds and fast-growing White Plymouth Rock (broiler) lines. Ikeobi et al. [8] have analysed a cross between a commercial broiler sire-line and a White Leghorn layer line, while Jennen et al. [10] have investigated crosses between two genetically different broiler lines. Each study has identified from 1-8 QTL for various fatness-related traits that range between 0.2-1.2 phenotypic standard deviations. These fatness QTL represent 26 loci that are dispersed across 14 chromosomes (Fig. 1).

Our analysis of genetic variation in fatness takes advantage of two experimental lines [fat (FL) and lean (LL) lines] that were divergently selected from a common genetic background established by mating six meat-type chicken strains [14]. The initial resource population was selected on abdominal fat weight of males at 9 weeks of age while body weight was maintained at the same level in both lines. In such lines, one can assume that the favourable alleles were fixed in each line during the selection process leading to a more powerful design for QTL analyses. This hypothesis is supported by the shape of the selection response curve which reached a plateau in the FL in the 4th generation and remained the same after selection was relaxed at the 7th generation [14]. However, the between line differences for the selected trait (abdominal fatness) have remained fairly constant (between 2-3 phenotypic standard deviations) throughout the subsequent generations. 

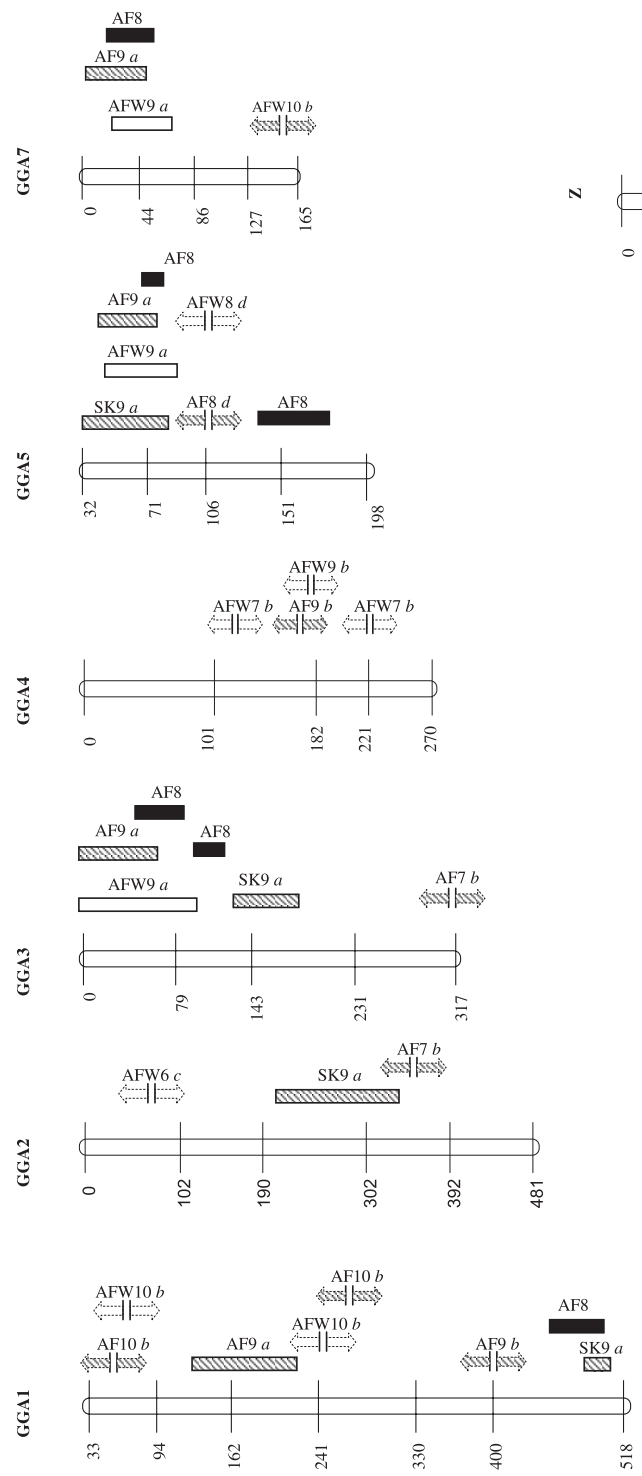
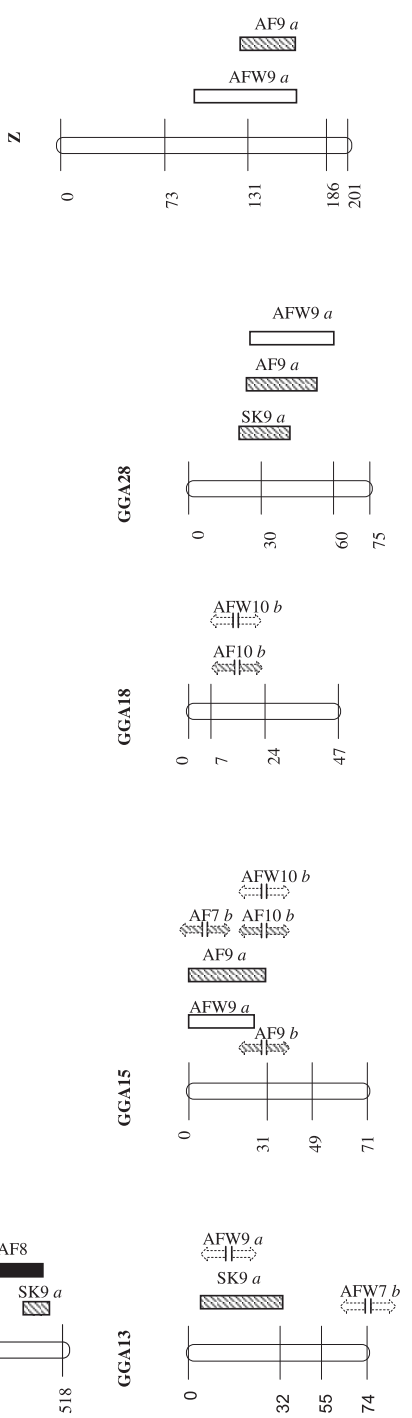

Figure 1. Chromosomal location of previously published and present QTL related to fatness. Three additional fatness QTL on GGA9 (AF9a), GGA11 (AFW7b) and GGA27 (AF9b) are not presented. AFx: abdominal fat weight adjusted for body weight at $x$ weeks of age. AFWx: abdominal fat weight (raw data) at $x$ weeks of age. SKx: skin weight adjusted to body weight at $x$ weeks of age. The boxes encompass the confidence interval of the QTL; When it is unknown, a broken arrow replaces the box. Black boxes: the present results; striped boxes: fat-related trait adjusted for body weight; empty boxes: raw data. ${ }^{\mathrm{a}}$ Ikeobi et al. [8]; ${ }^{\mathrm{b}} \mathrm{Jennen}$ et al. [10]; ${ }^{\mathrm{c}}$ McElroy et al. [21]; ' Tatsuda et al. [29]. 
For breeding of meat-type chickens, the main feature under selection for fast growth has been the amount of white meat produced (i.e., breast muscle weight). Breast muscle weight and meat yield are both highly heritable [12,23] as demonstrated in the selection of experimental lines [11]. Nonetheless, these two traits have been difficult to consider in breeding programmes, and like abdominal fatness, would benefit from advances in molecular genetics. However, only one QTL analysis for meat yield in chickens has been published so far [9]. Therefore, the present QTL analysis includes a search for both abdominal fatness and breast muscle QTL.

This paper describes QTL for abdominal fatness and breast muscle weight in an inter-cross of the divergently selected FL and LL.

\section{ANIMALS, MATERIALS AND METHODS}

\subsection{Animals}

A three-generation design was performed by inter-crossing two experimental meat-type chicken lines that were divergently selected on abdominal fatness and named [17] the fat (FL) and lean (LL) lines. In the $\mathrm{F}_{0}$ generation, 9 FL males were mated to 12 unrelated LL females to generate the $F_{1}$ generation. Five $F_{1}$ males were each mated to 7 or 8 unrelated $F_{1}$ dams (total of 38 birds) to produce $585 \mathrm{~F}_{2}$ progeny that were reared in four hatching groups. Blood was collected from all animals for DNA analyses.

The $\mathrm{F}_{2}$ chickens were fed ad libitum using conventional starter and grower broiler rations. At 8 weeks of age, the male offspring were slaughtered, and carcasses were eviscerated and stored at $4{ }^{\circ} \mathrm{C}$ for $20 \mathrm{~h}$ prior to dissection. Weights of abdominal fat and the breast muscle were recorded after dissection described by Marché [20]. The number of birds in sire-families 1, 2, 3, 4 and 5 were 114, 127, 116, 122 and 106, respectively. In the $F_{0}$ and $F_{1}$ generations, the same phenotypic traits were measured on male half-sib contemporaries with the breeders used in the crossing phase.

\subsection{Markers and genotyping}

DNA was purified from individual $100 \mu \mathrm{L}$ blood samples using a phenol/chloroform extraction modified for high throughput [1]. A total of $258 \mathrm{mi}$ crosatellite markers were chosen from the genetic consensus map [7] and were assessed for informativeness on the five $F_{1}$ sires. The 129 markers, chosen for the genotypings, were located on 26 chromosomes and 4 linkage groups 
described by Schmid et al. [26]. The markers spanned $2598 \mathrm{cM}$ with an average interval of $20 \mathrm{cM}$ between markers, including an arbitrary $20 \mathrm{cM}$ for end markers of each linkage group [8]. The markers covered about $86 \%$ of the genome, assuming $3800 \mathrm{cM}$ for the whole genome [7]. Two to 10 markers were combined according to size and amplification conditions for multiplex PCR amplification and analyses on an automated sequencer (ABI 3700, PE Applied Biosystems, Foster City, CA). The marker length and genotype of the animals were determined using GeneScan and Genotyper software (Applied Biosystems, Version 3.7).

A subset of the $\mathrm{F}_{2}$ birds was genotyped to reduce genotyping costs. Those individuals with the 40 most extreme values in each sire family (i.e., the 20 highest and 20 lowest values) were chosen for each trait, after correction for the effects of dam, hatch and 8-week body weight (see below). In total, $309 \mathrm{~F}_{2}$ birds (representing $53 \%$ of the $\mathrm{F}_{2}$ progeny) their $43 \mathrm{~F}_{1}$ parents and 21 grand-parents were genotyped using 129 informative markers.

\subsection{Statistical analyses}

Abdominal fat weight (AFW) and breast muscle weight (BMW) were adjusted in each sire family for dam and hatching group effects by twoway analysis of variance that included 8-week body weight as a covariate (GLM procedure of SAS ${ }^{\circledR}$ [24]), giving rise to the adjusted measurements (AF and BM, respectively). Ranking for identification of extreme birds was performed on the adjusted data. In order to assess the genetic variability available in the studied generation, heritabilities were estimated by nested analysis of variance, which included sire and dam effects (VARCOMP procedure of SAS $^{\circledR}$ [24]). Multipoint linkage analyses were carried out with the CriMap program, using the "build" option; map distances were expressed in Kosambi cM [6], actual distances were used in the QTL analyses. The distances were consistent with those of the consensus chicken map [7].

QTL interval mapping was performed with QTLmap software [13] which was developed for populations containing a mixture of full and half-sib families. QTLmap does not require any assumption about fixation of QTL in the founder population. The presence of the QTL was assessed using the ratio of likelihood under the hypothesis of one versus no QTL linked to a given set of markers [3]. Significance thresholds were determined empirically by simulating the data on a chromosome-wide basis and assuming a polygenic model. Up to 1000 simulations were performed for each trait $\times$ linkage group. 
Approximate confidence intervals of QTL position were determined empirically by the drop-off method [22].

The substitution effect of QTL alleles was estimated in each sire family at the position of maximum LR and the significance (difference to 0) was tested by the $t$-test using within-family residual standard error after removal of the QTL effect. The additive value of the QTL effect was assessed as the average of significant substitution effects. However, selective genotyping leads to over-estimation of QTL effects [19]. The relationship between the mean of the whole distribution and that of the selected animals can be expressed in a function depending on the percentage of selected extremes, assuming normal distribution. Numerical resolution of this relation allows us to assess the effect of selective genotyping on the estimation of QTL effects. (See Appendix for estimation of the effects of selective genotyping on QTL.) In the current study, only an upper limit of the over-estimation could be provided because the sets of selected birds included, for each trait, the extreme part for that trait plus some "random" animals, which were extremes for the other trait.

\section{RESULTS}

The average body, abdominal fat and breast muscle weights at 8 weeks of age for each generation are presented in Table I.

In order to assess genetic variability, apparent heritability and phenotypic correlation were measured in the $\mathrm{F}_{2}$ generation, despite the crossing design. Abdominal fat and breast muscle weights displayed a high phenotypic correlation with 8 -week body weight ( 0.45 and 0.83 , respectively); however, these correlations vanished when data were adjusted for 8-week body weight. AFW and BMW were significantly correlated ( $r=0.28)$, although the correlation was negative ( $r=-0.18$ ) after using the adjusted data (i.e., AF and BM). The "heritability" of adjusted performance was 0.83 and 0.82 for abdominal fat weight and breast muscle weight, respectively.

QTL interval mapping analysis was performed on the 309 extreme birds, in each $F_{1}$ sire progeny for both AF and BM traits. Two significant QTL for fatness were detected on chromosomes 1 and 5 and additional suggestive QTL were found on chromosomes 3, 5 and 7 (Tab. II). A single significant QTL for BM was found on GGA1, roughly at the same location as the AF QTL. The estimated effects of QTL ranged from $9.7 \mathrm{~g}-15.9 \mathrm{~g}$ for AF and was $21.7 \mathrm{~g}$ for BW (Tab. II). The over-estimation of QTL effects due to selective genotyping was assessed between 9-17\% according to the QTL, the higher the effect the lower the over-estimate (Tab. II). 
Table I. Means and standard deviations of production traits in male birds from parental lines and their crosses.

\begin{tabular}{cccc}
\hline Generation & BW $(\mathrm{g})$ & AFW $(\mathrm{g})$ & BMW $(\mathrm{g})$ \\
\hline LL $\left(\mathrm{F}_{0}\right)$ & $2126 \pm 178$ & $30.0 \pm 11^{\mathrm{a}}$ & $260 \pm 25^{\mathrm{a}}$ \\
FL $\left(\mathrm{F}_{0}\right)$ & $2009 \pm 175$ & $90.7 \pm 17^{\mathrm{b}}$ & $219 \pm 25^{\mathrm{b}}$ \\
$\mathrm{F}_{1}$ & $2699 \pm 87$ & $86.9 \pm 20.3$ & not recorded \\
$\mathrm{F}_{2}$ & $2122 \pm 184$ & $56.3 \pm 16$ & $257 \pm 31$ \\
\hline
\end{tabular}

BW: live body weight; AFW: abdominal fat weight; BMW: breast muscle weight. Trait values were measured at 9 weeks of age, except for the $F_{2}$ which were slaughtered at 8 weeks of age.

${ }^{\mathrm{a}, \mathrm{b}}$ Indicates that a mean for a same trait is significantly different $(P<0.001)$ between lines.

The QTL were identified in an analysis that included all families. However, depending on the QTL they were segregating (i.e., the QTL effect was significantly different from 0 ) in one to four out of five sire families (Tab. III). The origin of the fat QTL was from the FL, except in one family where the origin of a fatness QTL on GGA3 was from the LL. The origin of the high allele for the BM QTL on GGA1 was from either the LL or the FL (Tab. III).

\section{DISCUSSION}

The phenotypic measurements for parental LL and FL were similar to those reported in former generations of these lines after selection was relaxed [14]. The difference in abdominal fat weight between the $\mathrm{F}_{1}$ generation and $\mathrm{F}_{0}$ suggests dominance in the trait; however, the measurements were taken in $\mathrm{F}_{0}$ and $F_{1}$ birds that were raised at different times. A comparison with the $F_{2}$ values was also hampered by a difference in the age at slaughter ( 8 versus 9 weeks of age).

The apparent association between AFW and BMW (0.28) was likely due to the body weight factor, since it became negative $(-0.18)$ after adjustment for 8 week-body weight (AF and BM). This depicts the actual antagonism between fatness and meat yield. Thus, the adjusted data appears to be highly relevant when studying the potential for accumulating abdominal fat or breast muscle (white meat) in various QTL studies [8,10,21,25,28]. The high correlation between the weight of body parts and whole body weight (Tab. II; [2, 12]) could confound the identity of genes controlling variability in body weight with those involved in carcass composition variability. However, in experiments where both fat weight and fat ratio (or adjusted weight) have been explored $[8,10]$, 


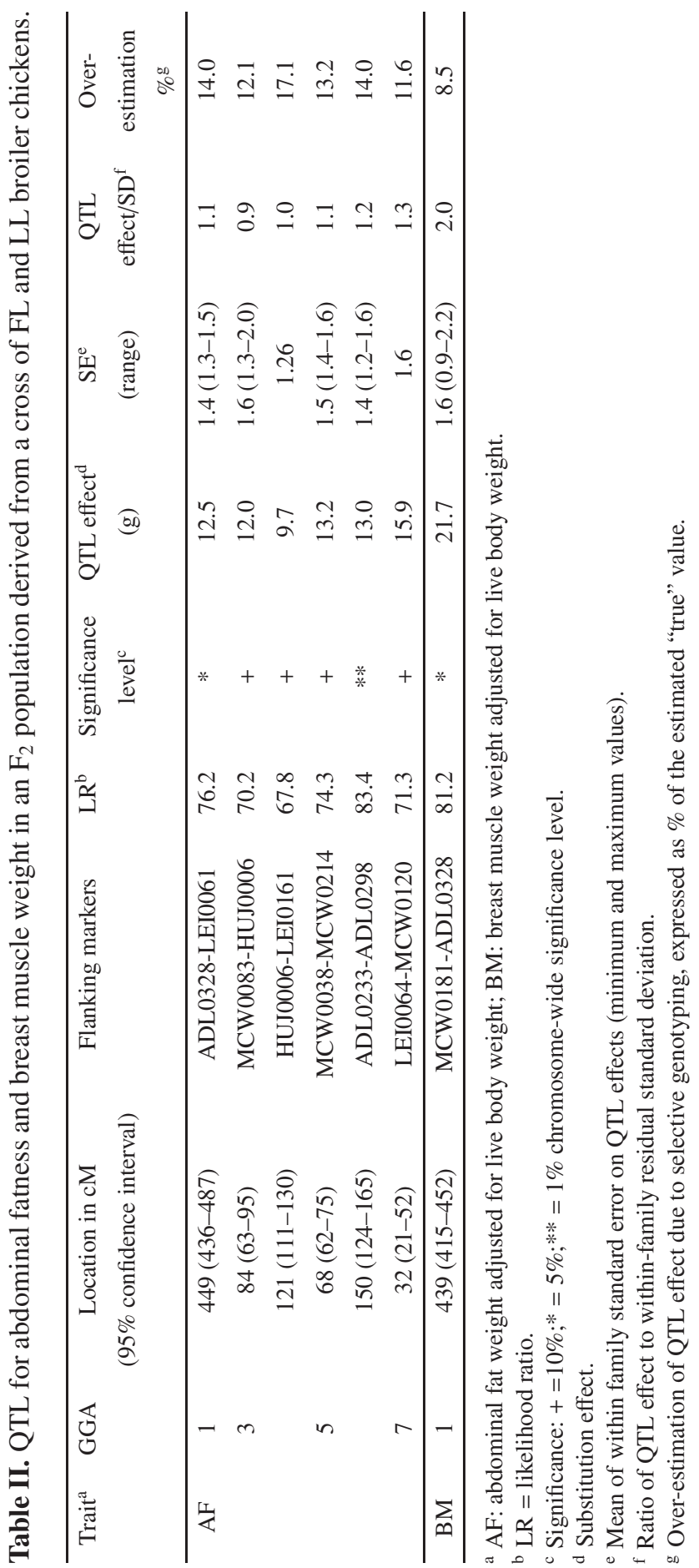


Table III. Segregation of QTL in each sire family and origin of the high allele.

\begin{tabular}{cccccc}
\hline Trait & GGA & $\begin{array}{c}\text { Location } \\
(\mathrm{cM})\end{array}$ & $\begin{array}{c}\text { Number of } \\
\text { sire families }\end{array}$ & $\begin{array}{c}\text { Sire family } \\
\text { number }\end{array}$ & $\begin{array}{c}\text { Origin of } \\
\text { high allele }\end{array}$ \\
\hline AF & 1 & 449 & 2 & $4-5$ & FL \\
& 3 & 84 & 4 & $2-3-5$ & FL \\
& & & & 1 & LL \\
& 3 & 121 & 1 & 2 & FL \\
& 5 & 68 & 3 & $2-3-5$ & FL \\
& 5 & 150 & 3 & $2-3-5$ & FL \\
& 7 & 32 & 1 & 3 & FL \\
\hline BM & 1 & 439 & 3 & $1-2$ & FL \\
& & & & 5 & LL
\end{tabular}

AF: abdominal fat weight adjusted for live body weight. BM: breast muscle weight adjusted for live body weight. FL: fat line. LL: lean line.

about half of the QTL were mapped to the same locations regardless of data adjustment (Fig. 1). This observation suggests that some pleiotropic genes control body size and carcass composition.

Although breast muscle weight was not directly taken into account during the selection process of the FL and LL, a correlated response was found for that trait according to the low and negative correlation observed between both traits adjusted for 8-week body weight (present results). This leads to a higher average BMW in the LL (Tab. I). This between-line variability contributes to the single QTL for BM on GGA1. There are three other reports that identify a single QTL for breast muscle yield or breast muscle weight on chromosome 2 (BM [21]), 4 (BMW [4]) and 8 (BM [9]). These relatively few QTL are all different which suggests that the QTL-dependent genetic variability for breast muscle is relatively low and specific to each genetic background.

We identified six QTL for abdominal fatness (AF), the high allele originated from the FL, except in one case from the LL, which suggests that the selection process actually increases the frequency in that particular line. However, these alleles have not been fixed as shown by a varing number of heterozygous families (one to four out of five sire families) for each AF QTL. This has occurred despite the dramatic selection response curve and the sustained between-line difference after the relaxation of selection [14]. It is possible that different combinations between alleles at various QTL could have led to the same targeted phenotype, which would prevent fixation of a favourable allele at each QTL locus. The situation was rather different with identification of only one breast muscle (BM) QTL, since the alleles seemed to segregate in 
each parental line, which could be explained by the absence of direct selection for this trait.

Fat QTL were found on chromosomes 1, 3, 5 and 7. Other QTL for fatness have been mapped on GGA1 [8,10], albeit at different locations (Fig. 1). Conversely, one region identified on chromosome 5 was also identified by Ikeobi et al. [8] for several other fat-related traits; however, it does not encompass $T G F \beta 3$ which is linked to AF [18], which seems to exclude it as a candidate gene. A similar situation occurred for fatness QTL on chromosomes 3 and 7. We suggest that the QTL regions identified in different genetic backgrounds include one or several genes which are highly important for the control of fatness variability, regardless of the genetic background.

The fatness QTL regions on GGA 5 include several genes related to lipid metabolism (i.e., lipoprotein receptors, fatty acid desaturases or transcription factors involved in regulation of fatty acid synthesis) (see http://www.ncbi.nlm.nih.gov/mapview/).

Despite these exciting possibilities, the fatness QTL identified so far extend over a wide region of the chicken genome $(\sim 50 \mathrm{cM})$ and include several hundred genes. The next critical steps in the search for genes responsible for variability in fatness will be to reduce the QTL region by appropriate methods (i.e., backcross experiments, identity by descent or linkage disequilibrium) prior to conducting detailed investigation of putative candidate genes.

\section{ACKNOWLEDGEMENTS}

The authors acknowledge the valuable technical support provided by the husbandry staff and the laboratory staff at the Station de recherches avicoles (INRA, Nouzilly), particularly J. Michel and G. Marché. We thank the technical staff of the Laboratoire de génétique cellulaire (INRA, Toulouse) and Unité de génétique animale (Agrocampus-INRA, Rennes) for their diligent assistance.

INRA, the Regional Council of Brittany, and the French Ministry in charge of Agriculture (DGER) supported this work. A grant from the USDA IFAFS programme (No. 00-52100-9614) contributed to the costs of genotyping.

\section{REFERENCES}

[1] Assaf S., Lagarrigue S., Daval S., Sansom M., Leclercq B., Michel J., Pitel F., Alizadeh M., Vignal A., Douaire M., Genetic linkage and expression analysis of SREBP and lipogenic genes in fat and lean chicken, Comp. Biochem. Physiol. B Biochem. Mol. Biol. 137 (2004) 433-441. 
[2] Chambers J.R., Genetics of growth and meat production in chickens, in: Crawford R.D. (Ed.), Poultry breeding and genetics, Elsevier, Amsterdam, 1990, pp. 599-643.

[3] Elsen J.M., Mangin B., Goffinet B., Boichard D., Le Roy P., Alternative models for QTL detection in livestock. I. General introduction, Genet. Sel. Evol. 31 (1999) 213-224.

[4] Gao Y., Hu X., Du Z., Liu Z., Feng J., Li N., Identification of quantitative trait loci for carcass composition in chicken using genomic scanning, in: XXIX International congress on animal genetics, 11 September 2004, Tokyo.

[5] Geraert P.A., MacLeod M.G., Larbier M., Leclercq B., Nitrogen metabolism in genetically fat and lean chickens, Poult. Sci. 69 (1990) 1911-1921.

[6] Green P., Falls K., Crooks S., Documentation for CRI-MAP version 2.4, Washington University School of Medicine, St Louis, MO, 1990.

[7] Groenen M.A., Cheng H.H., Bumstead N., Benkel B.F., Briles W.E., Burke T., Burt D.W., Crittenden L.B., Dodgson J., Hillel J., Lamont S., de Leon A.P., Soller M., Takahashi H., Vignal A., A consensus linkage map of the chicken genome, Genome Res. 10 (2000) 137-147.

[8] Ikeobi C.O., Woolliams J.A., Morrice D.R., Law A., Windsor D., Burt D.W., Hocking P.M., Quantitative trait loci affecting fatness in the chicken, Anim. Genet. 33 (2002) 428-435.

[9] Ikeobi C.O., Woolliams J.A., Morrice D.R., Law A., Windsor D., Burt D.W., Hocking P.M., Quantitative trait loci for meat yield and muscle distribution in a broiler layer cross, Livest. Prod. Sci. 87 (2004) 143-151.

[10] Jennen D.G., Vereijken A.L., Bovenhuis H., Crooijmans R.P., Veenendaal A., van der Poel J.J., Groenen M.A., Detection and localization of quantitative trait loci affecting fatness in broilers, Poult. Sci. 83 (2004) 295-301.

[11] Le Bihan-Duval E., Mignon-Grasteau S., Millet N., Beaumont C., Genetic analysis of a selection experiment on increased body weight and breast muscle weight as well as on limited abdominal fat weight, Br. Poult. Sci. 39 (1998) 346-353.

[12] Le Bihan-Duval E., Millet N., Remignon H., Broiler meat quality: effect of selection for increased carcass quality and estimates of genetic parameters, Poult. Sci. 78 (1999) 822-826.

[13] Le Roy P., Elsen J., Boichard D., Mangin B., Bidanel J.P., Goffinet B., An algorithm for QTL detection in mixture of full and half sib families, in: 6th World Congress on Genetics Applied to Livestock Production, 1998, Armidale, Vol. 26, pp. 257-260.

[14] Leclercq B., Genetic selection of meat-type chickens for high or low abdominal fat content, in: Leclercq B., Whitehead C.C. (Ed.), Leanness in domestic birds: genetic, metabolic and hormonal aspects, Butterworths-Inra, London, 1988, pp. 25-40.

[15] Leclercq B., Guy G., Further investigations on protein requirement of genetically lean and fat chickens, Br. Poult. Sci. 32 (1991) 789-798.

[16] Leclercq B., Whitehead C.C., Leanness in domestic birds: genetic, metabolic and hormonal aspects, Butterworths-Inra, London, 1988.

[17] Leclercq B., Blum J.C., Boyer J.P., Selecting broilers for low or high abdominal fat: initial observations, Br. Poult. Sci. 21 (1980) 107-113. 
[18] Li H., Deeb N., Zhou H., Mitchell A.D., Ashwell C.M., Lamont S.J., Chicken quantitative trait loci for growth and body composition associated with transforming growth factor-beta genes, Poult. Sci. 82 (2003) 347-356.

[19] Lynch M., Walsh B., Genetics and analysis of quantitative traits, Sinauer Associates Inc., Sunderland, MA, 1998.

[20] Marché G., La découpe anatomique et la dissection des volailles, Inra NouzillySYSAAF Nouzilly-Ofival Paris, 1995.

[21] McElroy J.P., Harry D.E., Dekkers J.C.M., Lamont S.J., Molecular markers associated with growth and carcass traits in meat-type chickens, in: 7th World Congress on Genetics Applied to Livestock Production, 19 August 2002, Montpellier.

[22] Ott J., Analysis of human genetic linkage, 2nd edn., John Hopkins University Press, Baltimore, 1991.

[23] Ricard F.H., Essai de sélection sur la forme de la courbe de croissance chez le poulet. Dispositif expérimental et premiers résultats, Ann. Génét. Sél. Anim. 7 (1975) 427-443.

[24] SAS $^{\circledR}$ Institute, SAS ${ }^{\circledR} /$ STATO User's Guide, version 6, SAS ${ }^{\circledR}$ Institute Inc., Cary, NC, 1989.

[25] Sato S.I., Odawara S., Nokaia H., Oyamada Y., Taguchi Y., Sasaki O., Isiiii K., Takeda H., Takahashi H., Minezawa M., Yanai S., Nirasawa K., Kobayashi E., Genetic mapping of quantitative trait loci affecting carcass traits in F2 intercross chickens, in: XXIX International congress on animal genetics, 11 September 2004, Tokyo.

[26] Schmid M., Nanda I., Guttenbach M., Steinlein C., Hoehn M., Schartl M., Haaf T., Weigend S., Fries R., Buerstedde J.M., Wimmers K., Burt D.W., Smith J., A'Hara S., Law A., Griffin D.K., Bumstead N., Kaufman J., Thomson P.A., Burke T., Groenen M.A., Crooijmans R.P., Vignal A., Fillon V., Morisson M., Pitel F., Tixier-Boichard M., Ladjali-Mohammedi K., Hillel J., Maki-Tanila A., Cheng H.H., Delany M.E., Burnside J., Mizuno S., First report on chicken genes and chromosomes 2000, Cytogenet. Cell Genet. 90 (2000) 169-218.

[27] Tatsuda K., Fujinaka K., Genetic mapping of the QTL affecting abdominal fat deposition in chickens, J. Poult. Sci. 38 (2001) 266-274.

[28] Tatsuda K., Fujinaka K., Genetic mapping of the QTL affecting body weight in chickens using a F2 family, Br. Poult. Sci. 42 (2001) 333-337.

[29] Tatsuda K., Fujinaka K., Kuroda Y., Specific DNA microsatellite marker allele affecting reduction of abdominal fat deposition in chickens, in: XXIX International congress on animal genetics, 11 September 2004, Tokyo.

[30] Van Kaam J.B., Groenen M.A., Bovenhuis H., Veenendaal A., Vereijken A.L., van Arendonk J.A., Whole genome scan in chickens for quantitative trait loci affecting carcass traits, Poult. Sci. 78 (1999) 1091-1099.

[31] Van Kaam J.B., Groenen M.A., Bovenhuis H., Veenendaal A., Vereijken A.L., van Arendonk J.A., Whole genome scan in chickens for quantitative trait loci affecting growth and feed efficiency, Poult. Sci. 78 (1999) 15-23.

[32] Van Kaam J.B., van Arendonk J.A., Groenen M.A., Bovenhuis H., Vereijken A.L., Crooijmans R.P., van der Poel J.J., Veenendaal A., Whole genome scan for 
quantitative trait loci affecting body weight in chickens using a three generation design, Livest. Prod. Sci. 54 (1998) 133-150.

\section{APPENDIX: ESTIMATION OF THE QTL EFFECT TAKING INTO ACCOUNT SELECTIVE GENOTYPING}

Following the notations of Elsen et al. [3], let $\alpha_{i}$ be the QTL substitution effect on the selected trait within the sire $i$ family. Noting 1 and 2 the QTL alleles of the sire $i, \alpha_{i}$ is the deviation between the means of the two distributions $f(x / 1)$ and $f(x / 2)$ of the trait within the two groups of progeny, having received 1 or 2 from their sire, respectively.

The selective genotyping being carried out on a proportion $q$ of the progeny, we have:

$$
q / 2=\int_{-\infty}^{-s}(1 / 2 f(x / 1)+1 / 2 f(x / 2))=\int_{s}^{+\infty}(1 / 2 f(x / 1)+1 / 2 f(x / 2))
$$

where: $s$ is the selection threshold in the distribution for a selection rate $q$, $f(x / 1)$ is distributed following the normal distribution $\mathrm{N}\left(\alpha_{i} / 2, \sigma_{i}^{2}\right)$, and $f(x / 2)$ is distributed following the normal distribution $\mathrm{N}\left(-\alpha_{i} / 2, \sigma_{i}^{2}\right)$.

The distribution for the genotyped progeny which have received 1 from their sire is:

$$
f(x / 1 \text { andselected })=f(x / 1) / f(\text { selected } / 1) .
$$

The expectation of this distribution, which is half of the $a_{i}$ QTL substitution effect estimated on the selected data, can then be written:

$$
E(x / 1 \text { andselected })=a_{i} / 2=\left(\int_{-\infty}^{-s} x f(x / 1)+\int_{s}^{+\infty} x f(x / 1)\right) / q .
$$

This gives:

$$
a_{i} / 2=\left(\alpha_{i} / 2\right)+\frac{\sigma_{i}}{q \sqrt{2 \pi}}\left(\exp \left\{-\left(\frac{s-\alpha_{i} / 2}{\sigma_{i}}\right)^{2}\right\}-\exp \left\{-\left(\frac{-s-\alpha_{i} / 2}{\sigma_{i}}\right)^{2}\right\}\right) .
$$

